\title{
Patient satisfaction and positive patient outcomes in ambulatory anesthesia
}

This article was published in the following Dove Press journal:

Ambulatory Anesthesia

9 April 2015

Number of times this article has been viewed

\section{Ushma Shah \\ David T Wong \\ Jean Wong}

Department of Anesthesia, Toronto Western Hospital, University Health Network, University of Toronto,

Toronto, ON, Canada
Correspondence: Jean Wong Department of Anesthesia, Toronto Western Hospital, University Health Network, 399 Bathurst St, Toronto, ON M5T 2S8, Canada

$\mathrm{Tel}+\mathrm{I} 4166035118$

Fax + I 4166036494

Email jean.wong@uhn.ca
Abstract: Most surgeries in North America are performed on an ambulatory basis, reducing health care costs and increasing patient comfort. Patient satisfaction is an important outcome indicator of the quality of health care services incorporated by the American Society of Anesthesiologists (ASA). Patient satisfaction is a complex concept that is influenced by multiple factors. A patient's viewpoint and knowledge plays an influential role in patient satisfaction with ambulatory surgery. Medical optimization and psychological preparation of the patient plays a pivotal role in the success of ambulatory surgery. Postoperative pain, nausea, and vomiting are the most important symptoms for the patient and can be addressed by multimodal drug regimens. Shared decision making, patient-provider relationship, communication, and continuity of care form the main pillars of patient satisfaction. Various psychometrically developed instruments are available to measure patient satisfaction, such as the Iowa Satisfaction with Anesthesia Scale and Evaluation du Vecu de I'Anesthesie Generale, but none have been developed specifically for ambulatory surgery. The ASA has made recommendations for data collection for patient satisfaction surveys and emphasized the importance of reporting the data to the Anesthesia Quality Institute. Future research is warranted to develop a validated tool to measure patient satisfaction in ambulatory surgery.

Keywords: patient, satisfaction, anesthesia, outcomes, questionnaire, perspectives

\section{Introduction}

Ambulatory surgery is an optimal environment for many surgical procedures; in fact, $70 \%$ of the surgeries in the United States and North America are being performed on an ambulatory basis. ${ }^{1,2}$ Ambulatory surgery has been defined as "an operation/procedure, excluding an office, outpatient operation or procedure, where the patient is discharged on the same working day". ${ }^{3}$ In North America, this may include "in-hospital stay less than 24 hours". 4

The increasing trend of ambulatory surgeries has emerged from advances in anesthesia and surgical techniques, and from rising health care costs. Due to these improvements in surgical and anesthetic techniques, traditional outcome measures such as morbidity and mortality are no longer sufficient markers of quality of care. Nontraditional patient-centered outcomes, such as patient satisfaction and postoperative recovery, are increasingly recognized as important indicators of the quality of health care. The assessment of patient satisfaction and recovery after ambulatory surgery will identify potential areas of improvement in care and quality. Patient satisfaction is an important part of quality of care, and various instruments have been developed to measure it. ${ }^{5}$ 
The aim of this review article is to discuss the patient's perception of ambulatory anesthesia and to define positive outcomes from the patient's viewpoint. Various methods to assess and achieve higher patient satisfaction will be reviewed.

\section{Methodology}

We performed a search of two databases, MEDLINE ${ }^{\circledR}$ (January 1946 until May 2014) and Embase (January 1947 until May 2014) using the following keywords: outpatient; ambulatory; day surgery; patient satisfaction; anaesthesia; anesthesia; and questionnaire. This search yielded 347 articles from MEDLINE and 207 articles from Embase. Abstracts of all the articles were reviewed, and 34 complete articles pertaining to ambulatory surgery were shortlisted for the review. Relevant references from the identified articles were also retrieved for analysis, and the manual searching of citation lists was also done. The search was limited to articles written in English and to the adult population (age more than 18 years).

\section{Patient perceptions and defining positive outcomes from the point of view of the patient \\ Patient perceptions}

The knowledge of patients' attitudes, beliefs, and perceptions will help to assess the quality of health care provided. ${ }^{6}$ By understanding patients' needs, we will be better equipped to meet their expectations. "Patient-centered care", a term coined by the Picker Institute in 1988, is now the basis of health care. ${ }^{7}$ The term was coined to shift the importance from illness, to the patient and his or her family. Keeping a patient's views, opinions, and perspectives at the center for the decisions and activities that affect them is vital. This was also stressed in the Crossing the Quality Chasm report of the Institute of Medicine. ${ }^{8} \mathrm{~A}$ recent retrospective case series revealed no significant difference in outcomes following outpatient cervical spine surgery when compared to conventional inpatient management. ${ }^{9}$ Similarly, a cohort study looking at outpatient versus inpatient total joint arthroplasty found no statistical difference for readmission, emergency room visits, or patient satisfaction. ${ }^{10}$ It is therefore unsurprising to note that Krywulak et a $\mathrm{l}^{11}$ noted statistically higher patient satisfaction following outpatient anterior cruciate ligament repair when compared with inpatient management.

Preoperative optimization and preparation of the patient is the key toward achieving successful outcomes of day surgery. This is particularly important as more complex surgeries and older patients with multiple comorbidities are being done on an ambulatory basis. ${ }^{12,13,14}$ In addition to ensuring that the patient is medically fit, the patient must be psychologically prepared for ambulatory surgery. Many individuals may have significant anxiety and apprehension associated with surgical interventions. ${ }^{15}$ The type of anesthesia used and the sex of the patient affects anxiety levels, as females are more anxious than males, and patients undergoing surgery under general anesthesia are more anxious than those undergoing surgery with local anesthesia. ${ }^{16}$ Patients are usually assessed days or weeks prior to the scheduled date of surgery either by preoperative nurses or anesthesiologists. This provides an opportunity to address a patient's fears and concerns. It also provides a stress-free environment where detailed information about the anesthesia is given, along with what to expect on the day of surgery. Anxiety levels could be reduced if preoperative information is matched with coping styles. ${ }^{17}$ Previous good experiences, perception of caring and security, and being well informed plays an important role in decreasing anxiety. ${ }^{18}$ Providing additional information in printed and video format also diminishes anxiety. ${ }^{19}$ Increasingly, patients want to be involved in making decisions about the type of anesthesia used - general anesthesia versus regional anesthesia - and, where appropriate, between conventional oral pain therapy versus catheter techniques..$^{20}$ Continuity of care with a familiar nurse throughout the perioperative journey from the preadmission procedure to awakening in the postanesthesia care unit also impacts one's perception of day surgery. ${ }^{21}$

\section{Postoperative outcomes}

With advances in surgical and anesthetic techniques, there is a low incidence of mortality and morbidity in day surgery. ${ }^{22-24}$ Warner et $\mathrm{a}^{22}$ conducted a prospective outcome survey of 38,598 patients who underwent 45,090 ambulatory procedures and reported the proportional risk of major morbidity (myocardial infarction, pulmonary embolism, respiratory failure, and central nervous system deficit) as 1:1,366 and death as 1:11,273. Unplanned hospital admission, readmission, and delayed discharge from recovery are yardsticks to measure outcomes. Mezei and Chung ${ }^{24}$ collected data on 17,638 patients undergoing day surgery and noted an overall readmission rate of $1.1 \%$. Ambulatory surgery has been shown to have a positive impact on health-related quality of life. ${ }^{25} \mathrm{~A}$ patient's recovery after ambulatory surgery plays a key role in determining a patient's quality of life and his or her ability to resume normal daily activities. Postoperative recovery is a multifaceted process including physiological endpoints, psychological status, and adverse events. 
Jenkins et a ${ }^{26}$ conducted a survey in 400 patients undergoing day surgery to elicit patients' preferences to avoid ten different postoperative outcomes. Patients chose the ability to shun postoperative pain, gagging on the endotracheal tube, nausea, and vomiting as their priority. Other outcomes that patients claimed to eschew were disorientation, shivering, sore throat, drowsiness, and thirst. Some studies have shown that patients' perceptions varied among the different sexes; females were more concerned about anesthesia than males. ${ }^{27}$ However, American Society of Anesthesiologists (ASA) grade, type of surgery, and previous anesthetic experience did not make any significant difference in patients' preferences. ${ }^{26,28}$

\section{Postoperative pain}

Postoperative pain is distressing to the patient. It prevents or disrupts sleep on the first postoperative day and is inversely related to physical activity. ${ }^{29}$ Chung et a $\mathrm{l}^{30}$ reported a $5.3 \%$ incidence of severe postoperative pain in the postanesthesia care unit and 24 hours postoperatively in a prospective study of 10,008 patients undergoing ambulatory surgery. McGrath et $\mathrm{al}^{31}$ found that $30 \%$ of patients experienced moderate to severe pain 24 hours after day surgery. Gramke et al ${ }^{32}$ conducted a study in 648 patients to evaluate their postoperative pain experience at home after ambulatory surgery. The authors found that operations on the nose, pharynx, abdomen, breast, and orthopedic procedures were most painful during the first 48 hours, and moderate to severe pain was experienced by $9 \%$ even after a 4-day period..$^{32}$ Thus, efforts must be made to provide consistent pain relief that is tailored to the type of surgery and to the individual needs of the patient. Younger patients, those with prior surgical experience, and those who received incomplete information are more likely to report pain. ${ }^{33}$

A combination of multimodal analgesia and local anesthetic techniques will help to enhance quality of pain relief. ${ }^{34}$ Nonopioid analgesics like acetaminophen and nonsteroidal anti-inflammatory agents are used as adjuvants to opioid analgesics before, during, and after surgery to enhance the recovery process and to provide good pain relief. Also, agents like gabapentinoids, alpha-2 agonists, ketamine, esmolol, and nonpharmacologic techniques like transcutaneous electrical nerve stimulation have been used for pain relief in day surgery. ${ }^{35,36}$ Single-shot and continuous peripheral nerve blocks (CPNBs) are well tolerated by the patients for ambulatory surgery. ${ }^{37}$ The duration of analgesia with a single-shot peripheral nerve block typically lasts $12-24$ hours, depending upon the drug, its concentration, and the volume of local anesthetic used. Recently, the use of adjuvants like dexamethasone in peripheral nerve blocks have shown to increase the duration of analgesia. ${ }^{38,39} \mathrm{CPNBs}$ provide higher quality of analgesia and better patient satisfaction when compared with opioid analgesia and single-shot peripheral nerve blocks. ${ }^{40,41}$ With appropriate patient selection, education, information (verbal and written), and follow-up, CPNB can be managed safely in an ambulatory settings. ${ }^{42-44}$ Patients and their caregivers must be educated and informed about the importance of continuing their analgesics as prescribed after discharge. This is also vital for patients who have received a single-shot peripheral nerve block in order to decrease pain intensity when the block wears off. Recently, studies of liposomal bupivacaine have shown that this drug has an extended duration of action, as well as a better safety profile compared to bupivacaine. ${ }^{45,46}$ These agents have great potential for improving postoperative analgesia in ambulatory surgery.

\section{Nausea and vomiting}

Postoperative nausea and vomiting (PONV) is an unpleasant experience and has been described as one of the most undesirable outcomes after anesthesia from a patient's perspective. ${ }^{26}$ In a multicenter study, Apfel et $\mathrm{al}^{47}$ reported an incidence of $37 \%$ for nausea and vomiting after discharge in ambulatory patients. It not only leads to delayed recovery and discharge from the ambulatory unit, but it also may be responsible for unplanned admission. Recently, the Society of Ambulatory Anesthesia (SAMBA) has updated its guidelines to avoid PONV ${ }^{48}$ The guidelines highlight the risk factors associated with PONV in adults and children, provides strategies to reduce baseline risks, and lists recommendations for the prophylaxis and treatment of PONV. The prophylaxis for PONV should be considered for patients with moderate risk (those who use one or two interventions) and high risk (those who use $>2$ interventions or a multimodal approach).

\section{Other outcomes}

Day surgery entrusts the care of the patient to him or herself. The presence of a responsible adult at home is vital in the first 24 hours for patient safety, as the cognitive, memory, and psychomotor functions of the patient may be impaired due to anesthetic or surgical factors. ${ }^{49}$ Delayed resumption of activities of daily living may result in greater caregiver burden..$^{50,51}$ With the aging population, increased caregiver burden may lead to patient dissatisfaction with ambulatory surgical care.

\section{Patient-based outcome measures}

A variety of patient-based outcome measures have been developed in chronic diseases like rheumatologic and 
musculoskeletal disorders. ${ }^{52,53}$ Recently, patient-centered outcomes of recovery after anesthesia and surgery have been developed and are increasingly being used to assess the effectiveness of interventions in clinical studies in anesthesia. ${ }^{54}$

The use of an instrument to assess postoperative recovery requires sound psychometric development that includes the patients' perspectives, not just health care providers' perspectives. There are eight criteria that have been proposed as necessary for patient-based outcome measures: appropriateness; reliability; validity; responsiveness; precision; interpretability; acceptability; and feasibility. ${ }^{53}$ Myles et al ${ }^{55}$ initially developed a Quality of Recovery (QoR) score that had nine items rated by the patient on a threepoint scale (scores ranging from 0 to 2 ). In order to improve validity and reliability, they then developed a 40-item questionnaire (QoR 40) incorporating five dimensions: patient support; comfort; emotions; physical independence; and pain, rated on a five-point Likert scale with scores ranging from 1-5 (maximum score: 200). ${ }^{56}$ QoR 40 showed good validity (construct and convergent), reliability, internal consistency, and responsiveness. QoR 40 is a high-quality tool that is used to measure recovery after anesthesia and surgery for both research and clinical practice. ${ }^{57}$ The time taken to complete QoR 40 was 6.3 minutes (standard deviation: 4.9 minutes). However, the QoR 40 is not specifically designed to measure recovery after ambulatory surgery. Recently, Stark et al ${ }^{58}$ developed QoR 15, a shorter version of QoR 40. The mean time to complete QoR 15 was 2.4 minutes. $^{58}$

The Functional Recovery Index (FRI) developed by Wong et $\mathrm{al}^{59}$ is an explicit tool for measuring recovery after ambulatory anesthesia. The FRI included 14 items covering three factors: pain and social activity; lower-limb activity; and general physical activity. Patients were interviewed during the item-generation phase of development to ensure that the patient's perspectives were included in this instrument. It had good validity, reliability, responsiveness, and acceptability. The time to complete the questionnaire was 4-4.5 minutes. Only the type of surgery (minor, intermediate, or major) was a significant predictor of the FRI. Age, ASA physical status, type of surgery, and duration of anesthesia did not affect the score.

There are various other postoperative recovery outcomes mentioned in the literature; however, most of them are not validated and have limitations. The Surgical Recovery Index focused primarily on pain and activities of daily living as their indicators of recovery, lacking postoperative symptoms related to mental health, fatigue, sleep, and the side effects of analgesics. ${ }^{54}$ The Post-discharge Surgical Recovery scale did not include cognitive functioning, mental health, and the side effects of analgesic agents. ${ }^{60}$ The General symptom distress scale was developed for home care, and the Functional status Questionnaire was developed for internal medicine clinics. ${ }^{61}$ The Postanesthesia Short-term Quality of Life tool (PASQOL) did not include pain and the side effects of analgesics in its determinants of quality of recovery. ${ }^{62}$ The 24-hour functional ability questionnaire did not include physical and psychosocial functioning; mental health was also not included. ${ }^{63}$

Recently, SAMBA has introduced the "SAMBA Clinical Outcomes Registry (SCOR)" database for ambulatory anesthesia. ${ }^{64}$ It forms a large database and helps to assess the quality of outcomes in comparison to national performance indicators.

\section{Patient satisfaction}

Patient satisfaction is an integral part of quality of outcomes. ${ }^{65,66}$ A patient's expectations forms the basis of his or her satisfaction. Traditionally, satisfaction has been defined as the correlation between expectation and accomplishment. ${ }^{67}$ Satisfaction is a complex, multidimensional concept influenced by cultural, sociodemographic, cognitive, and affective components. ${ }^{68}$

\section{Shared decision making}

Patient information and involvement in the decision-making process are some of the essential determinants of satisfaction. ${ }^{69-71}$ Studies have shown that patients show a strong preference $(65 \%)$ for totally balanced shared decision making as compared with the physicians $(32 \%) .{ }^{20}$ Patient satisfaction also correlated positively with the patient's perception of shared decision making. Higher scores were achieved when pain treatment was discussed in addition to the type of anesthesia - general or regional anesthesia, or both - in consultation. Our literature search revealed that patients are often satisfied with their care, even though clinicians have underestimated a patient's desire for information as long as they are a part of the decision-making process. ${ }^{72}$ The desire for shared decision making was associated with age (higher in younger patients) and education (those with higher levels of education), and is higher in patients who did not receive any premedication. ${ }^{73}$ Decision making may be aided with information leaflets explaining the risks and benefits of various types of anesthesia, videos, computer programs, preoperative counseling, and decision analysis models. ${ }^{74,75}$

\section{Sociodemographic factors}

Studies have shown that elderly patients are more satisfied than younger patients, and that females have a higher 
satisfaction rate than males. ${ }^{67-68}$ Ethnic groups vary in terms of their preferences, which may affect satisfaction. Hispanics gave higher preference to the courtesy of administrative staff, the level of comfort in the waiting area, and respect for privacy than whites or African-Americans. ${ }^{76}$ As well, a patient's health does influence his or her satisfaction; those with poor mental health appear to be related to lower satisfaction scores. Also, first-time visitors have lower satisfaction scores than do repeat patients. ${ }^{77}$

\section{Continuity of care}

Patients highly value the continuity of care provided by anesthesia care providers, which is defined as a single anesthesiologist that is involved from preoperative consultation, and who provides anesthesia and visits the patient in recovery after surgery. ${ }^{78}$ However, this type of care is not always possible in most day surgery centers due to work patterns and caseload. A prospective, randomized study performed by Saal et $\mathrm{al}^{79}$ showed that a single postoperative visit by the attending anesthesiologist increased the perception of continuity of care when compared with no visit at all. Similar results were seen when a visit was done by nurse anesthetist, provided that the patients were not expecting a physician. ${ }^{79}$

\section{Regional anesthesia}

Prior experience with regional anesthesia influences future anesthetic choices. The technique used (especially needle puncture) and success of the performance of regional anesthetic impacts patient satisfaction. ${ }^{80}$ Adequate sedation while performing the block and during the intraoperative period decreases the patient's anxiety and increases his or her acceptability of regional anesthesia. ${ }^{81}$ Also, postoperative regional analgesia resulted in greater patient satisfaction when compared with systemic analgesics. ${ }^{82}$ Among different regional anesthetic techniques, studies have shown that one particular technique may not significantly influence the degree of patient satisfaction. ${ }^{83}$ Spinal anesthesia with drugs like mepivacaine, low-dose bupivacaine, and ropivacaine have been suggested for ambulatory surgery. Studies have shown that low-dose ropivacaine allows for faster ambulation due to the shorter duration of the motor and sensory block, and it also provides recovery that is similar to desflurane anesthesia. ${ }^{84,85}$ However, patients do prefer general anesthesia if they have no previous surgical experience due to fear of intraoperative awareness. ${ }^{27}$ Reassurance that sedation will be provided may increase the acceptance of regional anesthesia techniques for ambulatory surgery.

\section{Other factors}

Prolonged waiting times between admission, operation, and discharge contributes to poor satisfaction scores. In the preoperative waiting period, patients are often anxious and nervous. They may feel abandoned if emotional and psychological support is not given by day surgery staff. ${ }^{86}$ Mui et $\mathrm{al}^{87}$ showed that patients need more emotional support and communication while undergoing regional anesthesia than general anesthesia. Privacy experienced by the patients also correlates positively with satisfaction. ${ }^{88}$ Patients feel vulnerable and powerless when their dignity and privacy are compromised. Education and information to help patients after discharge also increases their satisfaction. Specific information regarding pain management, potential postoperative complications, like surgical site infection, bleeding, recommendations of care, and a callback number, must be provided.

\section{Recording patient satisfaction}

Patient satisfaction is one of the outcome indicators included by the ASA Committee on Ambulatory and Office-Based Anesthesia. Many studies use simplistic questions to assess overall satisfaction, leading to falsely high scores. ${ }^{89-90}$ This includes questionnaires, telephone surveys, or face-to-face interviews. Questionnaires provide anonymous assessment, but at the price of a lower response rate. Interviews, on the other hand, may put patients under social pressure to answer positively, and they are associated with interviewer bias. ${ }^{91}$

The Agency for Healthcare Research and Quality created the Consumer Assessment of Healthcare Providers and Systems (CAHPS) - a standardized heath plan member satisfaction survey. ${ }^{92}$ The survey data impacts the payment of private insurers and government pay for performance plans. The American College of Surgeons developed a CAHPS survey for surgeons (S-CAHPS) that measures patients' experiences specific to surgery and anesthesia. Eight of the 45 questions in S-CAHPS are related to anesthesia. However, the ASA Committee on Performance and Outcome Measurement (CPOM) strongly recommends the revision of anesthesia-related questions in S-CAHPS, as the questions are inadequate to assess patient satisfaction with anesthesia. ${ }^{93}$

The ASA and its CPOM has produced recommendations for data collection with patient satisfaction surveys. ${ }^{93}$ This includes four data collection strategies: general information (survey type, mode, surgery date, response date, type of anesthesia, and surgery); demographic information (age, sex, education, race, and health status); as well as a short and long version of the anesthesia satisfaction survey. The survey was developed after a literature review conducted across all 
databases; CPOM members reviewed abstracts of relevant articles. Investigators applied the psychometric questionnaire steps described by Fung and Cohen ${ }^{89}$ to select studies. A core set of questions was developed from the actual survey questions after removing the duplicates. A modified Delphi technique was used to reach a consensus, and this was later reviewed by CPOM members. The short form of the survey includes questions from dimensions like information, shared decision making, pain management, anesthesia-related sequelae, and global satisfaction. In addition, the long form of the survey includes dimensions like attention and patientprovider relationship. The ASA recommends reporting this data to the Anesthesia Quality Institute. ${ }^{93}$ This survey has not been validated yet, and it was not specifically developed for ambulatory anesthesia and surgery.

Patient satisfaction is a complex, multifactorial concept and requires a reliable and valid tool for its evaluation. A high-quality psychometric instrument must be used to generate accurate data. ${ }^{89}$ This is a multistep process involving a literature review, conducting interviews with patients and experts, engaging in the development of a comprehensive item bank (content validity), translating aspects into practical questions, conducting a pilot study, and assessing validity (content, construct, criterion), reliability, practicability, and internal consistency. ${ }^{78}$

Barnett et $\mathrm{al}^{94}$ published a qualitative systematic review on patient satisfaction measures in anesthesia and have made recommendations for satisfaction questionnaires to be used in different clinical situations. The Iowa Satisfaction with Anesthesia Scale (ISAS) developed by Dexter et $\mathrm{al}^{95}$ demonstrates a robust development process with high patient and provider acceptability. ISAS was developed by input from anesthesiologists, experts in satisfaction questionnaire development, and from a literature search. It is recommended for monitored anesthesia care only. ${ }^{95} \mathrm{~A}$ perioperative questionnaire developed by Capuzzo et $\mathrm{al}^{96}$ and Bauer et $\mathrm{al}^{97}$ are used in the perioperative setting for quality improvement and included inpatients. The English adaptation of the Leiden Perioperative Care Patient Satisfaction questionnaire developed by Jlala et $\mathrm{al}^{98}$ consisted of inpatient orthopedic surgery patients. Similarly, the Heidelberg Perianesthetic questionnaire developed by Schiff et $\mathrm{al}^{70}$ included inpatients undergoing complex surgeries.

A systematic review to measure patient satisfaction with ambulatory anesthesia, as conducted by Chanthong et al, ${ }^{5}$ showed that only two questionnaires exhibited good psychometric properties. They were the Evaluation du Vecu de I'Anesthesie Generale (EVAN-G) and the ISAS. ${ }^{5}$
The EVAN-G includes 26 items, six specific scores, and one global index score. It correlated poorly with the age of the patient, ASA physical status, total anesthesia time, and previous anesthesia. It had good convergent validity, reliability, and reproducibility. The EVAN-G was developed from direct patient interviews and included both inpatients and ambulatory patients receiving general anesthesia. ${ }^{99}$ Evaluation du Vécu de l'Anesthésie LocoRégionale (EVAN-LR) is a perioperative satisfaction questionnaire developed for patients specifically undergoing regional anesthesia. ${ }^{100}$ The EVAN-LR consists of 19 items with five dimensions (including attention, information, discomfort, waiting, and pain) and a global index. Thus, there is currently not a valid or reliable questionnaire that has been developed and validated specifically to measure patient satisfaction in an ambulatory anesthesia setting; this is an area of future research.

\section{Consequences of patient satisfaction}

Patient satisfaction is directly related to the loyalty toward health care providers. ${ }^{101,102}$ A patient's perceptions of service quality also affects the financial earnings of the hospital. As well, satisfied patients are more prone to adhere to recommendations of the doctor and are less prone to file professional malpractice suits. A satisfied patient will also recommend the service to his or her friends and relatives. The monitoring of patient satisfaction is included in the payment for performance plans, and in the near future, this will affect payments for anesthesiologists in the US. ${ }^{103}$

\section{Alleviating patient concerns and guidance for achieving higher levels of patient satisfaction}

Information and communication are the keys to patient satisfaction. ${ }^{69,99}$ Shared decision making and respect for a patient's values, preferences, and expressed needs help to attain a high quality of care. ${ }^{104,105}$ Emotional support, a compassionate attitude, and a good doctor-patient relationship gain patient confidence. These soft skills, in addition to clinical acumen, are vital for a good patient experience. Also, good communication skills play a significant role in decreasing the anxiety of the patient. ${ }^{106}$

\section{Conclusion}

Ambulatory surgery entrusts the care of a patient into his/ her own hands. Assessing postoperative outcomes with dedicated, well-developed recovery tools and reporting them 
to a national database, such as the SCOR registry, helps to evaluate the quality of outcomes and compare them with other hospitals. The final outcome of comprehensive care is patient satisfaction. A psychometrically constructed questionnaire validated for a specific type of anesthetic must be used to gauge patient satisfaction in order to evaluate the quality of anesthetic care.

\section{Disclosure}

The authors report no conflicts of interest in this work.

\section{References}

1. Cullen KA, Hall MJ, Golosinskiy A. Ambulatory surgery in the United States, 2006. National health statistics reports; no 11. Hyattsville, MD: National Center for Health Statistics. 2009.

2. Britt LD, Hoyt DB, Jasak R, Jones RS, Drapkin J. Health care reform: impact on American surgery and related implications. Ann Surg. 2013;258(4):517-526.

3. International Association for Ambulatory Surgery. Ambulatory Surgery Handbook. Gent, Belgium Int Assoc Ambul Surg. 2013. Available at: http://www.iaas-med.com/files/2013/Day_Surgery_Manual.pdf. Accessed January 17, 2015.

4. Darwin L, Chung F. Patient selection for day surgery. Anaesth Intensive Care Med. 2013;14(3):114-118.

5. Chanthong P, Abrishami A, Wong J, Herrera F, Chung F. Systematic review of questionnaires measuring patient satisfaction in ambulatory anesthesia. Anesthesiology. 2009;110(5):1061-1067.

6. Davies AR, Ware JE. Involving consumers in quality of care assessment. Health Aff (Millwood). 1988;7(1):33-48.

7. Vuori H. Patient satisfaction-does it matter? Qual Assur Health Care. 1991;3(3):183-189.

8. Institute of Medicine. Crossing the Quality Chasm: A New Health System for the 21st Century. 2001.

9. Liu JT, Briner RP, Friedman JA. Comparison of inpatient vs. outpatient anterior cervical discectomy and fusion: a retrospective case series. BMC Surg. 2009;9(1):3.

10. Vegari DN, Mokris JG, Odum SM, Springer BD. Implications of Outpatient vs. Inpatient Total Joint Arthroplasty on Hospital Readmission Rates, Paper 367. Paper presented at: AAOS 2014 Annual Meeting; March 11-15; 2014; New Orleans, LA.

11. Krywulak SA, Mohtadi NGH, Russell ML, Sasyniuk TM. Patient satisfaction with inpatient versus outpatient reconstruction of the anterior cruciate ligament: a randomized clinical trial. Can J Surg. 2005;48(3):201-206.

12. Ansell GL. Outcome of ASA III patients undergoing day case surgery. Br J Anaesth. 2004;92(1):71-74.

13. Erickson M, Fites BS, Thieken MT, McGee AW. Outpatient anterior cervical discectomy and fusion. Am J Orthop (Belle Mead NJ). 2007;36(8):429-432.

14. Chung F, Mezei G, Tong D. Pre-existing medical conditions as predictors of adverse events in day-case surgery. Br J Anaesth. 1999;83(2):262-270.

15. Wetsch WA, Pircher I, Lederer W, et al. Preoperative stress and anxiety in day-care patients and inpatients undergoing fast-track surgery. $\mathrm{Br} \mathrm{J}$ Anaesth. 2009;103(2):199-205.

16. Mitchell M. Influence of gender and anaesthesia type on day surgery anxiety. $J A d v$ Nurs. 2012;68(5):1014-1025.

17. Mitchell M. Psychological preparation for patients undergoing day surgery. Ambul Surg. 2000;8(1):19-29.

18. Rosen S, Svensson M, Nilsson U. Calm or not calm: the question of anxiety in the perianesthesia patient. $J$ Perianesth Nurs. 2008;23(4):237-246.
19. Bondy LR, Sims N, Schroeder DR, Offord KP, Narr BJ. The effect of anesthetic patient education on preoperative patient anxiety. Reg Anesth Pain Med. 24(2):158-164.

20. Flierler WJ, Nübling M, Kasper J, Heidegger T. Implementation of shared decision making in anaesthesia and its influence on patient satisfaction. Anaesthesia. 2013;68(7):713-722.

21. Vogelsang J. Continued contact with a familiar nurse affects women's perceptions of the ambulatory surgical experience: a qualitativequantitative design. J Post Anesth Nurs. 1990;5(5):315-320.

22. Warner MA, Shields SE, Chute CG. Major morbidity and mortality within 1 month of ambulatory surgery and anesthesia. JAMA. 270(12): 1437-1441

23. Twersky R, Fishman D, Homel P. What happens after discharge? Return hospital visits after ambulatory surgery. Anesth Analg. 1997;84(2):319-324.

24. Mezei G, Chung F. Return hospital visits and hospital readmissions after ambulatory surgery. Ann Surg. 1999;230(5):721-727.

25. Mattila K, Lahtela M, Hynynen M. Health-related quality of life following ambulatory surgery procedures: assessment by RAND-36. BMC Anesthesiol. 2012;12:30.

26. Jenkins K, Grady D, Wong J, Correa R, Armanious S, Chung F. Postoperative recovery: day surgery patients' preferences. Br J Anaesth. 2001;86(2):272-274.

27. Shevde K, Panagopoulos G. A survey of 800 patients' knowledge, attitudes, and concerns regarding anesthesia. Anesth Analg. 1991;73(2):190-198.

28. Klafta JM, Roizen MF. Current understanding of patients' attitudes toward and preparation for anesthesia: a review. Anesth Analg. 1996;83(6):1314-1321.

29. Pavlin DJ, Chen C, Penaloza DA, Buckley FP. A survey of pain and other symptoms that affect the recovery process after discharge from an ambulatory surgery unit. J Clin Anesth. 2004;16(3): 200-206.

30. Chung F, Ritchie E, Su J. Postoperative pain in ambulatory surgery. Anesth Analg. 1997;85(4):808-816.

31. McGrath B, Elgendy H, Chung F, Kamming D, Curti B, King S. Thirty percent of patients have moderate to severe pain $24 \mathrm{hr}$ after ambulatory surgery: a survey of 5,703 patients. Can J Anaesth. 2004;51(9):886-891.

32. Gramke H-F, de Rijke JM, van Kleef M, et al. The prevalence of postoperative pain in a cross-sectional group of patients after day-case surgery in a university hospital. Clin J Pain. 2007;23(6):543-548.

33. Bandyopadhyay M, Markovic M, Manderson L. Women's perspectives of pain following day surgery in Australia. Aust $J$ Adv Nurs. 2007;24(4):19-23.

34. Schug SA, Chong C. Pain management after ambulatory surgery. Curr Opin Anaesthesiol. 2009;22(6):738-743.

35. Elvir-Lazo OL, White PF. Postoperative pain management after ambulatory surgery: role of multimodal analgesia. Anesthesiol Clin. 2010;28(2):217-224.

36. Elvir-Lazo OL, White PF. The role of multimodal analgesia in pain management after ambulatory surgery. Curr Opin Anaesthesiol. 2010;23(6):697-703.

37. Ilfeld BM, Esener DE, Morey TE, Enneking FK. Ambulatory perineural infusion: the patients' perspective. Reg Anesth Pain Med. 2003;28(5):418-423.

38. Rahangdale R, Kendall MC, McCarthy RJ, et al. The effects of perineural versus intravenous dexamethasone on sciatic nerve blockade outcomes: a randomized, double-blind, placebo-controlled study. Anesth Analg. 2014;118(5):1113-1119.

39. Choi S, Rodseth R, McCartney CJL. Effects of dexamethasone as a local anaesthetic adjuvant for brachial plexus block: a systematic review and meta-analysis of randomized trials. $\mathrm{Br} J$ Anaesth. 2014;112(3):427-439.

40. Richman JM, Liu SS, Courpas G, et al. Does continuous peripheral nerve block provide superior pain control to opioids? A meta-analysis Anesth Analg. 2006;102(1):248-257. 
41. Bingham AE, Fu R, Horn J-L, Abrahams MS. Continuous peripheral nerve block compared with single-injection peripheral nerve block: a systematic review and meta-analysis of randomized controlled trials. Reg Anesth Pain Med. 37(6):583-594.

42. Ilfeld BM. Continuous peripheral nerve blocks: a review of the published evidence. Anesth Analg. 2011;113(4):904-925.

43. Swenson JD, Bay N, Loose E, et al. Outpatient management of continuous peripheral nerve catheters placed using ultrasound guidance: an experience in 620 patients. Anesth Analg. 2006;103(6):1436-1443.

44. Swenson JD, Cheng GS, Axelrod DA, Davis JJ. Ambulatory anesthesia and regional catheters: when and how. Anesthesiol Clin. 2010;28(2):267-280.

45. Chahar P, Cummings KC. Liposomal bupivacaine: a review of a new bupivacaine formulation. J Pain Res. 2012;5:257-264.

46. Portillo J, Kamar N, Melibary S, Quevedo E, Bergese S. Safety of liposome extended-release bupivacaine for postoperative pain control. Front Pharmacol. 2014;5:90.

47. Apfel CC, Philip BK, Cakmakkaya OS, et al. Who is at risk for postdischarge nausea and vomiting after ambulatory surgery? Anesthesiology. 2012;117(3):475-486.

48. Gan TJ, Diemunsch P, Habib AS, et al. Consensus guidelines for the management of postoperative nausea and vomiting. Anesth Analg. 2014;118(1):85-113.

49. Ip HYV, Chung F. Escort accompanying discharge after ambulatory surgery: a necessity or a luxury? Curr Opin Anaesthesiol. 2009;22(6):748-754.

50. Bryson GL, Clavel NA, Moga R, Power B, Taljaard M, Nathan HJ. Patient function and caregiver burden after ambulatory surgery: a cohort study of patients older than 65. Can J Anaesth. 2013;60(9): 864-873.

51. Manohar A, Cheung K, Wu CL, Stierer TS. Burden incurred by patients and their caregivers after outpatient surgery: a prospective observational study. Clin Orthop Relat Res. 2014;472(5):1416-1426.

52. Garratt A, Schmidt L, Mackintosh A, Fitzpatrick R. Quality of life measurement: bibliographic study of patient assessed health outcome measures. BMJ. 2002;324(7351):1417.

53. Fitzpatrick R, Davey C, Buxton MJ, Jones DR. Evaluating patient-based outcome measures for use in clinical trials. Health Technol Assess. 1998;2(14):i-iv, 1-74.

54. Talamini MA, Stanfield CL, Chang DC, Wu AW. The Surgical Recovery Index. Surg Endosc. 2004;18(4):596-600.

55. Myles PS, Hunt JO, Nightingale CE, et al. Development and psychometric testing of a quality of recovery score after general anesthesia and surgery in adults. Anesth Analg. 1999;88(1):83-90.

56. Myles PS, Weitkamp B, Jones K, Melick J, Hensen S. Validity and reliability of a postoperative quality of recovery score: the QoR-40. $\mathrm{Br}$ J Anaesth. 2000;84(1):11-15.

57. Gornall BF, Myles PS, Smith CL, et al. Measurement of quality of recovery using the QoR-40: a quantitative systematic review. $\mathrm{Br} \mathrm{J}$ Anaesth. 2013;111(2):161-169.

58. Stark PA, Myles PS, Burke JA. Development and psychometric evaluation of a postoperative quality of recovery score: the QoR-15. Anesthesiology. 2013;118(6):1332-1340.

59. Wong J, Tong D, De Silva Y, Abrishami A, Chung F. Development of the functional recovery index for ambulatory surgery and anesthesia. Anesthesiology. 2009;110(3):596-602.

60. Kleinbeck S V. Self-reported at-home postoperative recovery. Res Nurs Health. 2000;23(6):461-472.

61. Swan BA, Maislin G, Traber KB. Symptom distress and functional status changes during the first seven days after ambulatory surgery. Anesth Analg. 1998;86(4):739-745.

62. Oakes CL, Ellington KJ, Oakes KJ, Olson RL, Neill KM, Vacchiano CA. Assessment of postanesthesia short-term quality of life: a pilot study. AANA J. 2002;70(4):267-273.

63. Hogue SL, Reese PR, Colopy M, et al. Assessing a tool to measure patient functional ability after outpatient surgery. Anesth Analg. 2000;91(1):97-106.
64. SAMBA Clinical Outcomes Registry. Available at: http://scordata.org/. Accessed June 14, 2014.

65. Fleisher LA, Mantha S, Roizen MF. Medical technology assessment: an overview. Anesth Analg. 1998;87(6):1271-1282.

66. Cleary PD, McNeil BJ. Patient satisfaction as an indicator of quality care. Inquiry. 1988;25(1):25-36.

67. Pascoe GC. Patient satisfaction in primary health care: a literature review and analysis. Eval Program Plann. 1983;6(3-4):185-210.

68. Aharony L, Strasser S. Patient satisfaction: what we know about and what we still need to explore. Med Care Rev. 1993;50(1):49-79.

69. Heidegger T, Husemann Y, Nuebling M, et al. Patient satisfaction with anaesthesia care: development of a psychometric questionnaire and benchmarking among six hospitals in Switzerland and Austria. $\mathrm{Br} J$ Anaesth. 2002;89(6):863-872.

70. Schiff JH, Fornaschon AS, Frankenhauser S, et al. The Heidelberg Perianaesthetic Questionnaire-development of a new refined psychometric questionnaire. Anaesthesia. 2008;63(10):1096-1104.

71. Caljouw MAA, van Beuzekom M, Boer F. Patient's satisfaction with perioperative care: development, validation, and application of a questionnaire. Br J Anaesth. 2008;100(5):637-644.

72. Strull WM, Lo B, Charles G. Do patients want to participate in medical decision making? JAMA. 1984;252(21):2990-2994.

73. Spies CD, Schulz CM, Weiss-Gerlach E, et al. Preferences for shared decision making in chronic pain patients compared with patients during a premedication visit. Acta Anaesthesiol Scand. 2006;50(8):1019-1026.

74. Lee A, Chui PT, Gin T. Educating patients about anesthesia: a systematic review of randomized controlled trials of media-based interventions. Anesth Analg. 2003;96(5):1424-1431, table of contents.

75. Yentis SM. Decision analysis in anaesthesia: a tool for developing and analysing clinical management plans. Anaesthesia. 2006;61(7):651-658.

76. Dolinsky AL, Stinerock R. Cultural affiliation and the importance of health care attributes. Marketers can develop segmentation strategies for targeted patient groups. Mark Health Serv. 1998;18(1):28-37.

77. Kaldenberg DO, Becker BW. Evaluations of care by ambulatory surgery patients. Health Care Manage Rev. 1999;24(3):73-83.

78. Heidegger T, Saal D, Nuebling M. Patient satisfaction with anaesthesia care: what is patient satisfaction, how should it be measured, and what is the evidence for assuring high patient satisfaction? Best Pract Res Clin Anaesthesiol. 2006;20(2):331-346.

79. Saal D, Heidegger T, Nuebling M, Germann R. Does a postoperative visit increase patient satisfaction with anaesthesia care? Br J Anaesth. 2011;107(5):703-709.

80. De Andrés J, Valía JC, Gil A, Bolinches R. Predictors of patient satisfaction with regional anesthesia. Reg Anesth. 20(6):498-505.

81. Van Vlymen JM, Sá Rêgo MM, White PF. Benzodiazepine premedication: can it improve outcome in patients undergoing breast biopsy procedures? Anesthesiology. 1999;90(3):740-747.

82. Schug SA, Fry RA. Continuous regional analgesia in comparison with intravenous opioid administration for routine postoperative pain control. Anaesthesia. 1994;49(6):528-532.

83. Wu CL, Naqibuddin M, Fleisher LA. Measurement of patient satisfaction as an outcome of regional anesthesia and analgesia: a systematic review. Reg Anesth Pain Med. 26(3):196-208.

84. Buckenmaier CC, Nielsen KC, Pietrobon R, et al. Small-dose intrathecal lidocaine versus ropivacaine for anorectal surgery in an ambulatory setting. Anesth Analg. 2002;95(5):1253-1257, table of contents.

85. Lennox PH, Chilvers C, Vaghadia H. Selective spinal anesthesia versus desflurane anesthesia in short duration outpatient gynecological laparoscopy: a pharmacoeconomic comparison. Anesth Analg. 2002;94(3):565-568; table of contents.

86. Gilmartin J, Wright K. Day surgery: patients' felt abandoned during the preoperative wait. J Clin Nurs. 2008;17(18):2418-2425.

87. Mui W-C, Chang C-M, Cheng K-F, et al. Development and validation of the questionnaire of satisfaction with perioperative anesthetic care for general and regional anesthesia in Taiwanese patients. Anesthesiology. 2011;114(5):1064-1075. 
88. Bain J, Kelly H, Snadden D, Staines H. Day surgery in Scotland: patient satisfaction and outcomes. Qual Health Care. 1999;8(2):86-91.

89. Fung D, Cohen MM. Measuring patient satisfaction with anesthesia care: a review of current methodology. Anesth Analg. 1998;87(5):1089-1098.

90. Ware JE, Snyder MK, Wright WR, Davies AR. Defining and measuring patient satisfaction with medical care. Eval Program Plann. 1983; 6(3-4):247-263

91. Phellas C, Bloch A, Seale C. Structured methods: Interviews, questionnaires and observation. Available at: http://www.sagepub.com/ upm-data/47370_Seale_Chapter_11.pdf. Accessed January 17, 2015.

92. Consumer Assesment of Healthcare Providers and Systems. Available at: https:/cahps.ahrq.gov/. Accessed January 16, 2015.

93. Macdonald, N Obrien S. Patient Satisfaction and Experience with Anesthesia. Available at: http://www.aqihq.org/files/ASA_Membership_Patient_Satisfaction.pdf. Accessed July 14, 2014.

94. Barnett SF, Alagar RK, Grocott MPW, Giannaris S, Dick JR, Moonesinghe SR. Patient-satisfaction measures in anesthesia: qualitative systematic review. Anesthesiology. 2013;119(2):452-478.

95. Dexter F, Aker J, Wright WA. Development of a measure of patient satisfaction with monitored anesthesia care: the Iowa Satisfaction with Anesthesia Scale. Anesthesiology. 1997;87(4):865-873.

96. Capuzzo M, Landi F, Bassani A, Grassi L, Volta CA, Alvisi R. Emotional and interpersonal factors are most important for patient satisfaction with anaesthesia. Acta Anaesthesiol Scand. 2005;49(6):735-742.

97. Bauer M, Böhrer H, Aichele G, Bach A, Martin E. Measuring patient satisfaction with anaesthesia: perioperative questionnaire versus standardised face-to-face interview. Acta Anaesthesiol Scand. 2001;45(1):65-72.
98. Jlala HA, Caljouw MA, Bedforth NM, Hardman JG. Patient satisfaction with perioperative care among patients having orthopedic surgery in a university hospital. Local Reg Anesth. 2010;3:49-55.

99. Auquier P, Pernoud N, Bruder N, et al. Development and validation of a perioperative satisfaction questionnaire. Anesthesiology. 2005;102(6):1116-1123.

100. Maurice-Szamburski A, Bruder N, Loundou A, Capdevila X, Auquier P. Development and validation of a perioperative satisfaction questionnaire in regional anesthesia. Anesthesiology. 2013; 118(1):78-87.

101. Woodside AG, Frey LL, Daly RT. Linking service quality, customer satisfaction, and behavioral intention. J Health Care Mark 1989;9(4):5-17.

102. Nelson EC, Rust RT, Zahorik A, Rose RL, Batalden P, Siemanski BA. Do patient perceptions of quality relate to hospital financial performance? J Health Care Mark. 1992;12(4):6-13.

103. Liu EHC. Linking pay and performance. Br J Anaesth. 2013;111(4): 526-528.

104. Barry MJ, Edgman-Levitan S. Shared decision making-pinnacle of patient-centered care. N Engl J Med. 2012;366(9):780-781.

105. Stiggelbout AM, Van der Weijden T, De Wit MPT, et al. Shared decision making: really putting patients at the centre of healthcare. $B M J$. 2012;344:e256.

106. Harms C, Young JR, Amsler F, Zettler C, Scheidegger D, Kindler CH. Improving anaesthetists' communication skills. Anaesthesia. 2004;59(2):166-172.
Ambulatory Anesthesia

\section{Publish your work in this journal}

Ambulatory Anesthesia is an international, peer reviewed, open access journal publishing articles that address all aspects of ambulatory anesthesia practice, in particular: anesthetic techniques, sedation and safety practices, pharmacokinetics, preoperative evaluation, analgesia interventions, regulatory and compliance issues, postoperative recovery,

\section{Dovepress}

patient satisfaction, administrative topics, and cost analysis themes. The manuscript management system is completely online and includes a very quick and fair peer review system, which is all easy to use. Visit http://www.dovepress.com/testimonials.php to read real quotes from published authors. 